\title{
pH-Dependent Spectroscopy and Electronic Structure of the Guanine Analogue 6,8-Dimethylisoxanthopterin ${ }^{\dagger}$
}

\author{
Eleanore Seibert, ${ }^{\ddagger}$ Alexander S. Chin, ${ }^{\ddagger}$ Wolfgang Pfleiderer, ${ }^{\S}$ Mary E. Hawkins," \\ William R. Laws, ${ }^{\dagger, \perp}$ Roman Osman, $* \#$ and J. B. Alexander Ross $*,, \perp$ \\ Departments of Pharmacology and Biological Chemistry and Physiology and Biophysics, Mount Sinai School \\ of Medicine, One Gustave L. Levy Place, New York, New York 10029, Facultät für Chemie, Universität \\ Konstanz, Konstanz, Germany, Pediatric Oncology Branch, National Cancer Institute, Bethesda, Maryland \\ 20892, and Department of Chemistry, University of Montana, Missoula, Montana 59812
}

Received: September 3, 2002; In Final Form: October 28, 2002

\begin{abstract}
Fluorescent nucleic acid analogues are valuable tools for studying DNA dynamics, protein-DNA interactions and nucleotide-dependent enzyme activities. The recent development of guanine analogues based on the isoxanthopterin structure offers new opportunities to investigate these dynamics, interactions, and activities. Our combined experimental/theoretical investigation of one such analogue, 6,8-dimethylisoxanthopterin (6,8DMI), has shown that absorbance and fluorescence emission spectra of 6,8DMI shift to lower energies as the $\mathrm{pH}$ is increased, yielding $\mathrm{p} K_{\mathrm{a}}$ values of 8.3 and 8.5, respectively. We show that these $\mathrm{pH}$-dependent spectral changes result from protonation/deprotonation of the nitrogen at position 3 of $6,8 \mathrm{DMI}$ on the basis of $\mathrm{pH}$-dependent iodide ion quenching of 6,8DMI fluorescence and $\mathrm{pH}$-independent absorption and fluorescence properties of 3,6,8-trimethylisoxanthopterin. Quantum mechanical calculations on the neutral and deprotonated forms of 6,8DMI confirm the observed spectral changes.
\end{abstract}

\section{Introduction}

The study of DNA structure, dynamics, and interactions with proteins is critical to understand biological processes such as replication, transcription, recombination, and repair. Fluorescence spectroscopy is an effective method for examining conformation and dynamics as well as binding interactions. However, due to efficient quenching by internal conversion, ${ }^{1}$ the naturally occurring DNA bases have very low fluorescence quantum yields, and thus are not suitable reporters for most fluorescence experiments. Therefore, extrinsic and pseudo intrinsic fluorescent probes have been widely used to study DNA structure and dynamics. Pseudo intrinsic probes, in which the fluorophore is covalently bound to the sugar moiety, replacing the normal base group, have several advantages over extrinsic probes. Pseudo intrinsic probes can be placed at different, known positions within the DNA sequence, which allows investigation of local DNA properties such as flexibility and stacking interactions. Furthermore, these probes can be designed to mimic the natural DNA bases and thus minimally perturb the DNA structure.

\footnotetext{
Abbreviations: 6,8DMI, 6,8-dimethylisoxanthopterin; DNA, deoxyribonucleic acid; 2AP, 2-aminopurine; 3MI, 3-methylisoxanthopterin; 6MI, 6-methylisoxanthopterin; 3,6,8TMI, 3,6,8-trimethylisoxanthopterin; TDDFT, time-dependent density functional theory; MP2, Møller-Plesset second-order perturbation theory; CI, configuration interaction; PCM, polarized continuum model; HOMO, highest occupied molecular orbital; LUMO. lowest unoccupied molecular orbital.

* To whom correspondence should be addressed. R.O.: tel., (212) 241 5609; fax, (212) 860-3369; e-mail, Roman.Osman@mssm.edu. J.B.A.R.: tel., (406) 243-6026; fax, (406) 243-4227; e-mail, sandy@ selway.umt.edu.

Department of Pharmacology and Biological Chemistry, Mount Sinai School of Medicine.

$\S$ Universität Konstanz.

"National Cancer Institute.

$\perp$ University of Montana.

\# Department of Physiology and Biophysics, Mount Sinai School of Medicine.
}

The fluorescent adenine analogue, 2-aminopurine (2AP), is an example of a well-studied pseudo intrinsic fluorescent probe that may be incorporated in DNA or RNA. 2AP has been widely used to study DNA and RNA conformation, ${ }^{2,3}$ DNA dynamics, ${ }^{4}$ DNA-protein interactions, ${ }^{5}$ and DNA glycosylase activity. ${ }^{6,7}$ The availability of fluorescent analogues of other DNA bases would be beneficial to the investigation of local DNA properties, as it would then be possible to probe additional sites. Such probes would be particularly advantageous when investigating sequence-specific processes, such as DNA repair.

Hawkins and co-workers have described substituted pteridines as fluorescent analogues of DNA bases (see ref 8 for review), and they have identified 3-methylisoxanthopterin (3MI) and 6-methylisoxanthopterin (6MI) as two particularly promising guanine analogues. Both analogues have absorbance bands that are at lower energies (red-shifted) than those of the naturally occurring nucleic acids and amino acids, allowing selective excitation of the analogues. The free analogues have high fluorescence quantum yields with lifetimes of approximately 6 ns, thus making them useful for fluorescence studies of biological molecules. Incorporation into DNA reduces the quantum yield and average fluorescence lifetime in a sequencedependent manner. ${ }^{9,10}$ To assess whether introduction of the analogues perturbs DNA structure, melting temperatures, $T_{\mathrm{m}}$, of oligonucleotides containing these probes were compared to those containing guanine. ${ }^{9}$ In the case of $3 \mathrm{MI}$, the $T_{\mathrm{m}}$ was reduced a few degrees, because the methyl group on N3 abolishes one hydrogen bonding contact with the complementary cytosine. In contrast, when $6 \mathrm{MI}$ was opposite cytosine, the $T_{\mathrm{m}}$ was not significantly affected, indicating that all three expected hydrogen bonds are maintained. Thus, $6 \mathrm{MI}$ is not expected to greatly perturb DNA structure.

Hawkins et al. previously reported a $\mathrm{pH}$-dependent change in the emission spectra of $6 \mathrm{MI}$ and suggested that deprotonation 
at N3 occurs near physiological pH. ${ }^{9}$ Deprotonation of the analogue in DNA could result in perturbation of local structure. However, in double-stranded DNA, there may be a preference for the neutral $6 \mathrm{MI}$ because the $\mathrm{H} 3$ is involved in hydrogen bonding. Base flipping or other local perturbations of DNA structure may alter the $\mathrm{p} K_{\mathrm{a}}$ of this group. Such effects could have significant implications in the interpretation of spectroscopic data involving 6MI in DNA.

To characterize the protonation states of $6 \mathrm{MI}$, we have examined 6,8-dimethylisoxanthopterin $(6,8 \mathrm{DMI})$, in which the deoxyribose is replaced by a methyl group to avoid possible interactions with the sugar moiety. Specifically, we evaluated the ground-state and lowest energy excited-state equilibria by using absorbance and fluorescence spectroscopies, respectively. Essentially, the same $\mathrm{p} K_{\mathrm{a}}$ is observed in both the ground and excited states, suggesting no change in proton equilibrium during the lifetime of the excited state. The absorbance and fluorescence properties of the control compound 3,6,8-trimethylisoxanthopterin $(3,6,8 \mathrm{TMI})$ were found to be nearly identical to those of the neutral $6,8 \mathrm{DMI}$ species, confirming that the deprotonation occurs at its N3. Time-dependent density functional theory (TDDFT) has been used to characterize the electronic structure and spectroscopic properties of the neutral and negatively charged forms of $6,8 \mathrm{DMI}$, and then these properties were compared with those calculated for 3,6,8TMI.

\section{Materials and Methods}

Spectroscopy. The base analogues 6,8DMI and 3,6,8TMI were prepared as described previously. ${ }^{11}$

Absorption spectra were measured using a dual-beam U-3210 Hitachi spectrophotometer and quartz cuvettes with a $1 \mathrm{~cm}$ path length. Baselines were measured with the appropriate buffer, described below. Steady-state emission spectra were obtained using an SLM4800 spectrofluorometer modified for singlephoton counting. Excitation wavelengths used for 6,8DMI and 3,6,8TMI were 342 and $349 \mathrm{~nm}$, respectively. Emission spectra were collected over the range of $360-550 \mathrm{~nm}$, with a gate time of $3 \mathrm{~s}$ for $1 \mathrm{~nm}$ increments. Band-passes were $4 \mathrm{~nm}$ for both excitation and emission monochromators. Absorbance of samples at the excitation wavelength was less than 0.02, and hence primary inner filter effects were negligible. Fluorescence intensities were determined by integrating the spectra over the entire wavelength range.

Time-resolved fluorescence decay curves were collected using a time-correlated, single-photon counting instrument described previously. ${ }^{12}$ Fluorescence lifetimes of samples were measured in an automated sample chamber (Quantum Northwest: FLASC) using vertically polarized light at $360 \mathrm{~nm}$. The emission at 420 nm was selected by a monochromator (Acton SpectroPro-150; $10 \mathrm{~nm}$ band-pass) after passing through a polarizer oriented at the magic angle. ${ }^{13}$ The instrument response function was measured using a dilute suspension of colloidal silica. Decay curves were collected into 2000 channels with a timing calibration of $24.2 \mathrm{ps}$ per channel. Instrument response functions and decay curves were collected to 100000 and 40000 peak counts, respectively.

Time-resolved fluorescence data were analyzed by a standard reconvolution ${ }^{14}$ procedure using nonlinear regression. ${ }^{15}$ Each fluorescence decay curve could be fit by a single exponential as judged by the $\chi^{2}$ statistical parameter and random distributions of the weighted residuals and their autocorrelation. Joint support plane confidence intervals were calculated for all iterated parameters by the approximation method described by Johnson and co-workers. ${ }^{16}$
KI Quenching. A fresh stock solution of $1 \mathrm{M}$ KI was prepared daily at the appropriate $\mathrm{pH}$, and $\mathrm{Na}_{2} \mathrm{~S}_{2} \mathrm{O}_{3}\left(\sim 1 \times 10^{-4}\right.$ M) was added to prevent the formation of $\mathrm{I}_{3}{ }^{-}$. KI quenching data were analyzed according to the Stern-Volmer equation: ${ }^{13}$

$$
\tau_{0} / \tau=1+K_{\mathrm{SV}}[\mathrm{Q}]
$$

where $\tau$ is the lifetime for a given concentration of quencher, $\mathrm{Q}, \tau_{0}$ is the lifetime in the absence of quencher and $K_{\mathrm{SV}}$ is the Stern-Volmer constant. The bimolecular quenching constant, $k_{\mathrm{q}}$, is calculated from the relationship

$$
k_{\mathrm{q}}=K_{\mathrm{SV}} / \tau_{0}
$$

pH Titrations. The buffers used were $\mathrm{HCl}$ ( $\mathrm{pH}$ 1.0-3.0), $50 \mathrm{mM}$ citric acid ( $\mathrm{pH} 4.0), 10 \mathrm{mM}$ sodium pyrophosphate $(\mathrm{pH}$ 5.0-6.0, 8.0-10.0), and $\mathrm{NaOH}(\mathrm{pH} \mathrm{11.0-13.0).} \mathrm{The} \mathrm{stock}$ solutions of the probes, which were used for absorption measurements, were prepared at each $\mathrm{pH}$ value by dissolution in deionized $\mathrm{H}_{2} \mathrm{O}$ followed by 1:2 dilution into the appropriate buffer. Samples for fluorescence titrations were generated by measuring the absorbance of the buffered solution and then diluting with buffer to achieve the desired concentration of probe.

The $\mathrm{p} K_{\mathrm{a}}$ was determined by fitting the fraction ionized, $Y$, to the Henderson-Hasselbalch equation:

$$
Y=\frac{10^{\left(\mathrm{pH}-\mathrm{p} K_{\mathrm{a}}\right)}}{1+10^{\left(\mathrm{pH}-\mathrm{p} K_{\mathrm{a}}\right)}}
$$

using the nonlinear regression routine in SPSS. ${ }^{17}$ The goodness of the fit was judged by the $R^{2}$ parameter, which was greater than 0.99 in each case.

Computational Methods. All calculations were performed using Gaussian98. ${ }^{18}$ Ground-state geometries of the 3,6,8TMI and the negative ion of 6,8DMI were optimized using MøllerPlesset (MP2) perturbation theory with the 6-31G+(d) basis set and assuming $C_{s}$ symmetry. We have recently reported the ground- and excited-state geometries of the neutral form of $6,8 \mathrm{DMI}{ }^{19}$ and these were used as starting structures for the geometry optimizations of the 6,8DMI anion, and 3,6,8TMI. The geometry of the $\pi \pi^{*}$ emitting state was optimized using configuration interaction (CI) singles and allowing the molecule to assume a nonplanar geometry.

TD-DFT, as represented in Gaussian98, ${ }^{18}$ was used to calculate transition energies and oscillator strengths at the optimized absorbing and emitting geometries. The B3LYP functional was used with a $6-31 \mathrm{G}+(\mathrm{d})$ basis set. Electronic properties were calculated in vacuum as well as with the polarized continuum model $(\mathrm{PCM})^{20,21}$ representing water as the solvent, using Pauling's atomic radii, and 1.2 as the scaling factor for the definition of solvent accessible surfaces. ${ }^{18}$ Molecular orbitals were visualized with MOLEKEL. ${ }^{22,23}$

\section{Results and Discussion}

Experimental Results. Previously reported fluorescence emission spectra and decay-associated spectra of 6MI-deoxyribose revealed $\mathrm{pH}$-dependent spectroscopic changes. ${ }^{9}$ To characterize the spectroscopic properties of this guanosine analogue and to probe the hypothesis that the $\mathrm{pH}$ dependence is due to an excited-state deprotonation reaction, ${ }^{9}$ we have recorded absorbance spectra as a function of $\mathrm{pH}$. To eliminate complicating effects that the deoxyribose moiety may have on the spectroscopic properties of the probe, the present studies focus on 6,8DMI, in which a methyl group replaces the 

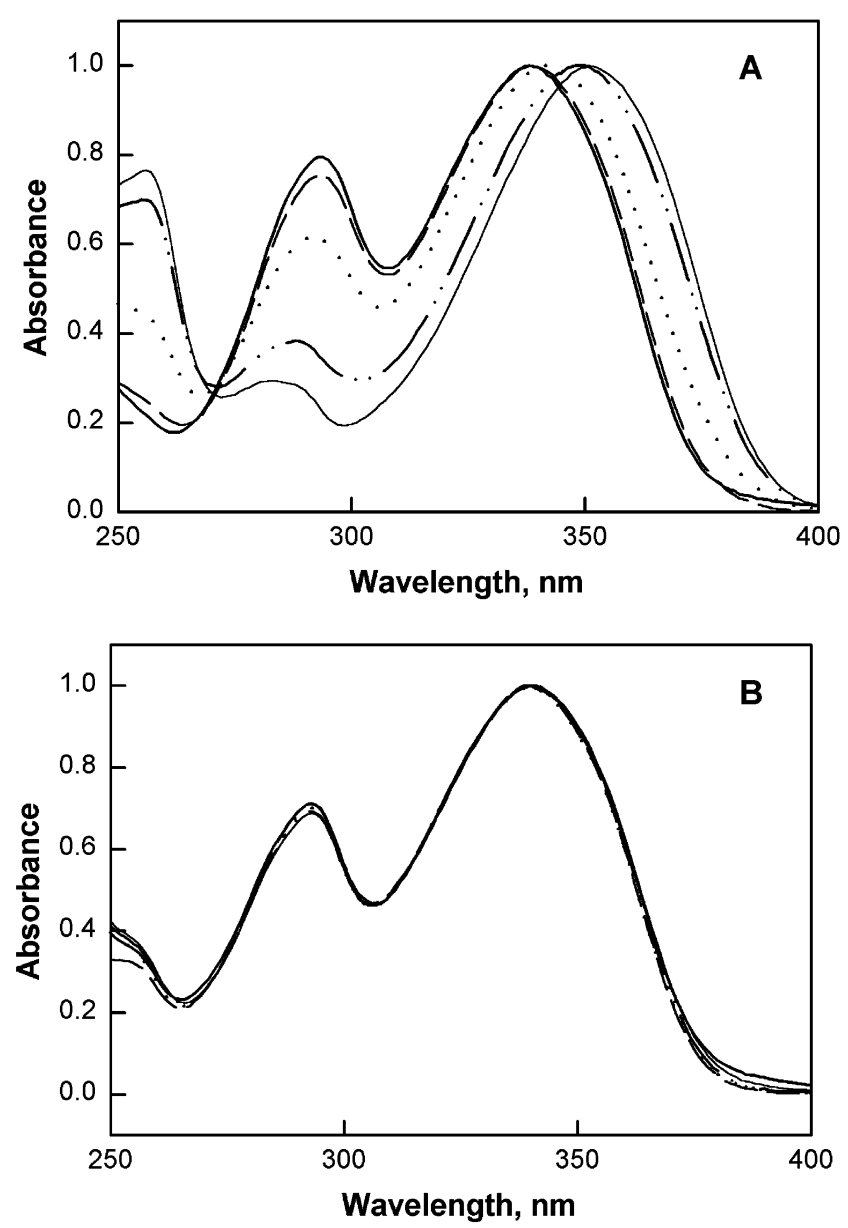

Figure 1. Absorbance spectra of 6,8DMI (A) and 3,6,8TMI (B) at pH $1(-), \mathrm{pH} 7.5(--), \mathrm{pH} 8(\cdots), \mathrm{pH} 9(-\cdots-)$, and $\mathrm{pH} 12(-)$.

deoxyribose. Absorbance spectra of 6,8DMI were collected as a function of $\mathrm{pH}$ in the range between 1 and 13; selected spectra are shown in Figure 1A. At each $\mathrm{pH}$, two absorbance bands are observed in the wavelength region above $275 \mathrm{~nm}$. There is no change in absorbance observed between $\mathrm{pH} 1$ and 6. Below $\mathrm{pH}$ 6, peak maxima occur at 338 and $294 \mathrm{~nm}$. At higher $\mathrm{pH}$, the lower energy band shifts to longer wavelengths, and the extinction of the higher energy band decreases. In addition, an isosbestic point occurs at $271 \mathrm{~nm}$, which suggests a two-state protonation equilibrium in the ground state. By contrast, no changes in absorbance spectra were observed for 3,6,8TMI over the same $\mathrm{pH}$ range (Figure $1 \mathrm{~B}$ ). The absorbance spectrum of 3,6,8TMI has similar maxima, 339 and $293 \mathrm{~nm}$, as 6,8DMI at low $\mathrm{pH}$, suggesting that the $\mathrm{pH}$-dependent absorbance change is due to deprotonation of 6,8DMI at N3 (Scheme 1).

The absorbance spectrum of 6,8DMI measured at each $\mathrm{pH}$ was then fit as a linear combination of two basis spectra ${ }^{24}$ using those obtained at $\mathrm{pH} 5$ and $\mathrm{pH} 11$ as the basis set. The

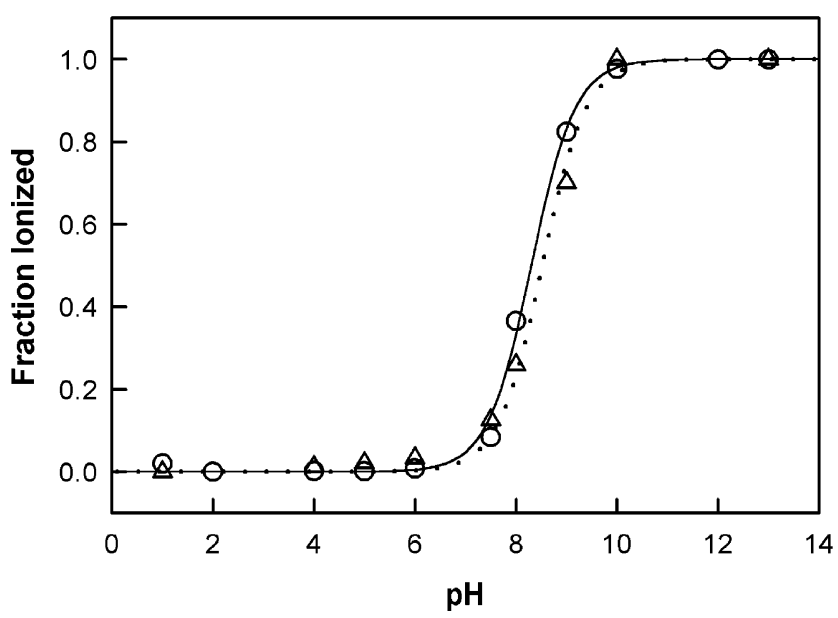

Figure 2. Fraction of 6,8DMI ionized at various $\mathrm{pH}$ values obtained from the coefficients of the analysis of absorbance $(O)$ and emission $(\triangle)$ spectra at each $\mathrm{pH}$ as linear combinations of basis spectra at $\mathrm{pH} 5$ and $\mathrm{pH} 11$. Lines represent the best fit of the absorbance (-) and emission ( $\cdots)$ data to the Henderson-Hasselbalch equation.

coefficients of the basis spectra were then used to determine the fraction of 6,8DMI ionized at each $\mathrm{pH}$ (Figure 2). Fitting the fraction ionized to the Henderson-Hasselbalch equation (eq 1) yielded a $\mathrm{p} K_{\mathrm{a}}$ of $8.30 \pm 0.07$ for $6,8 \mathrm{DMI}$ in the electronic ground state. The deprotonation of guanine at the analogous $\mathrm{N} 1$ has a $\mathrm{p} K_{\mathrm{a}}$ of $9.2 .^{25}$ The difference between these two $\mathrm{p} K_{\mathrm{a}}$ values is consistent with the electron-withdrawing pyrazine ring providing greater stabilization of the $6,8 \mathrm{DMI}$ anion than is provided by the imidazole ring of guanine.

To determine whether the excited-state $\mathrm{p} K_{\mathrm{a}}$ of $6,8 \mathrm{DMI}$ differs from its ground-state $\mathrm{p} K_{\mathrm{a}}$, fluorescence emission spectra of 6,8DMI and 3,6,8TMI collected over the $\mathrm{pH}$ range from 1 to 13 were compared; several representative spectra are shown in Figure 3 . From $\mathrm{pH} 1$ to 6 , there is essentially no change in the emission spectrum of 6,8DMI, which has a maximum at 410 $\mathrm{nm}$ (Figure 3A). As $\mathrm{pH}$ is increased further, however, the position of the maximum shifts to longer wavelengths. At $\mathrm{pH}$ 11 or greater, the maximum of the spectrum is observed at 427 $\mathrm{nm}$. No change in the emission spectrum of 3,6,8TMI, which has a maximum at $413 \mathrm{~nm}$, was observed over the same $\mathrm{pH}$ range (Figure 3B). The fraction of 6,8DMI ionized was calculated by fitting each emission spectrum as a linear combination of two basis spectra; as before, spectra obtained at $\mathrm{pH} 5$ and 11 were selected as the basis set. Fitting the fraction ionized to the Henderson-Hasselbalch equation (eq 1) yielded a $K_{\mathrm{a}}$ of $8.52 \pm 0.11$ (Figure 2), in agreement with the $\mathrm{p} K_{\mathrm{a}}$ obtained from the absorbance data. Thus, there does not appear to be a significant change in the equilibrium of species during the excited-state lifetime. We therefore conclude that the observed changes in emission spectra may be explained by the presence of neutral and anionic 6,8DMI in the ground state, both of which can be excited and subsequently emit. Conse-

\section{SCHEME 1: Protonation States of 6,8DMI}<smiles>Cc1nc2c(=O)[nH]c(N)nc2n(C)c1=O</smiles>

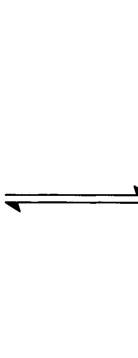<smiles>Cc1nc2c(=O)[nH]c(N)nc2n(C)c1=O</smiles> 

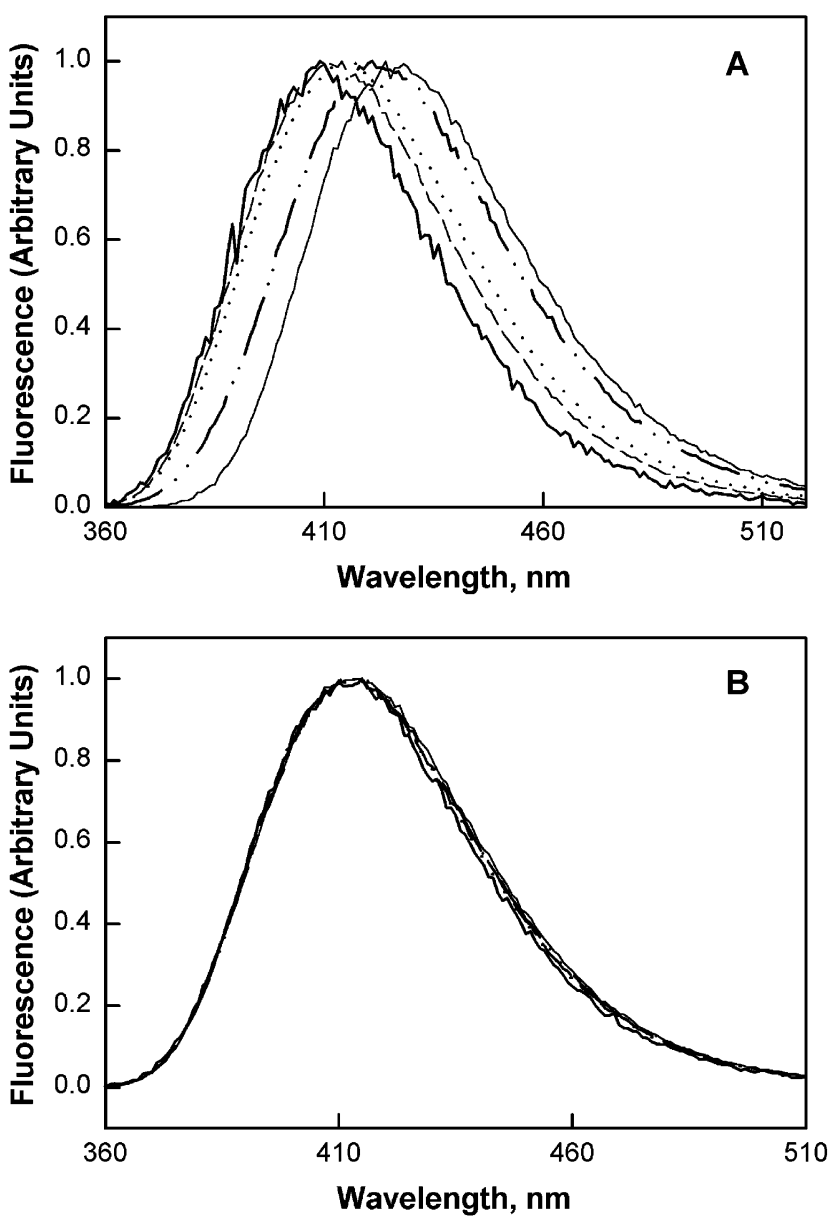

Figure 3. Fluorescence emission spectra of 6,8DMI (A) and 3,6,8TMI (B) at $\mathrm{pH} 1(-), \mathrm{pH} 7.5(--), \mathrm{pH} 8(\cdots) \mathrm{pH} 9(-\cdots-)$, and $\mathrm{pH} 12$ $(-)$.

quently, an excited-state reaction model is not necessary to describe the changes in the spectra that occur due to deprotonation of $6,8 \mathrm{DMI}$.

To confirm that $6,8 \mathrm{DMI}$ is shifting from a neutral species to an anion at increased $\mathrm{pH}$, iodide quenching of fluorescence was performed at $\mathrm{pH} 5$ and $\mathrm{pH} 11$. Given a $K_{\mathrm{a}}$ of $8.3-8.5,>99 \%$ of the neutral and the anionic form of $6,8 \mathrm{DMI}$ are present at pH 5 and 11, respectively. Because of electrostatic repulsion, the negatively charged iodide ion should quench the anionic species less efficiently than the neutral species. As a control, $3,6,8 \mathrm{TMI}$ was used because its fluorescence and protonation state are constant over the range of $\mathrm{pH}$ values used. SternVolmer plots ${ }^{13}$ of the iodide quenching of 6,8DMI and 3,6,8TMI (Figure 4) were generated from the fluorescence lifetime of the probes measured as a function of KI concentration. The slope of the Stern-Volmer plots for 3,6,8TMI does not vary significantly from $\mathrm{pH} 5$ to $\mathrm{pH} 11$. However, there is significant variation in slope of the plots for $6,8 \mathrm{DMI}$ as a function of $\mathrm{pH}$. The slope alone does not report the efficiency of quenching, because the slope is equal to the product of the bimolecular quenching rate constant and the lifetime in the absence of quencher (eq 2), and the fluorescence lifetime may be $\mathrm{pH}$ dependent. The observed fluorescence lifetime of 6,8DMI in the absence of quencher is $5.60 \pm 0.01 \mathrm{~ns}$ at $\mathrm{pH} 5$ and $6.55 \pm$ $0.01 \mathrm{~ns}$ at $\mathrm{pH} 11$, whereas the lifetime of $3,6,8 \mathrm{TMI}$ is $\mathrm{pH}$ independent $(5.64 \pm 0.01 \mathrm{~ns}$ at $\mathrm{pH} 5$ and $5.66 \pm 0.01 \mathrm{~ns}$ at $\mathrm{pH}$ 11). Fluorescence lifetimes and bimolecular quenching constants are presented in Table 1. A 2.5-fold decrease in $k_{\mathrm{q}}$ for iodide quenching of $6,8 \mathrm{DMI}$ is observed when the $\mathrm{pH}$ increases from

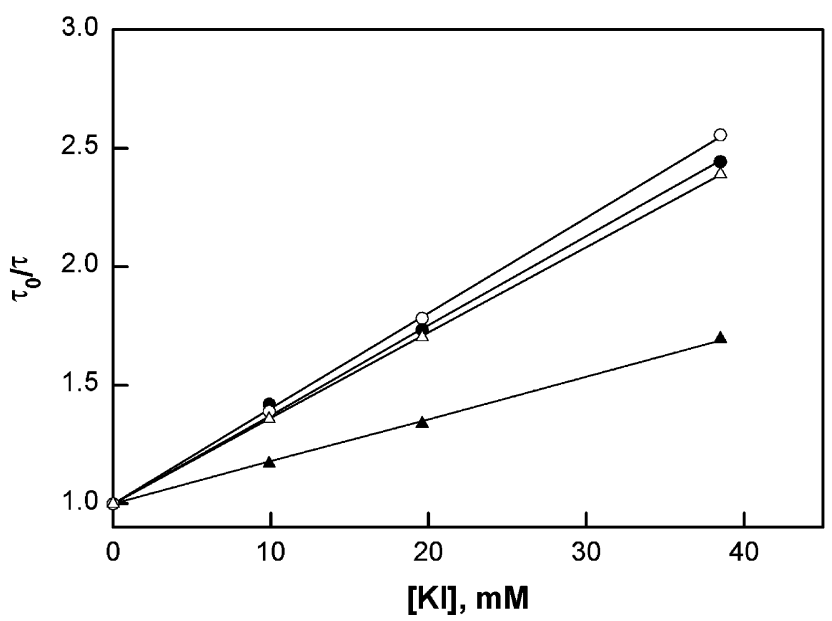

Figure 4. Stern-Volmer plots for the quenching of 6,8DMI at $\mathrm{pH} 5$ $(\bullet)$ and $\mathrm{pH} 11(\boldsymbol{\Delta})$ and 3,6,8TMI at $\mathrm{pH} 5(\mathrm{O})$ and $\mathrm{pH} 11(\triangle)$ with iodide ion. Solid lines represent fits to the Stern-Volmer equation (eq 2).

TABLE 1: KI Quenching of 6,8DMI and 3,6,8TMI ${ }^{a}$

\begin{tabular}{lccc}
\hline \multicolumn{1}{c}{ species } & $K_{\text {sv }}\left(\mathrm{M}^{-1}\right)$ & $\tau_{0}(\mathrm{~ns})$ & $10^{-9} k_{\mathrm{q}}\left(\mathrm{M}^{-1} \mathrm{~s}^{-1}\right)$ \\
\hline 6,8DMI, pH 5 & $37.74 \pm 1.96$ & $5.60 \pm 0.01$ & $6.74 \pm 0.35$ \\
6,8DMI, pH 11 & $17.97 \pm 0.72$ & $6.55 \pm 0.01$ & $2.73 \pm 0.11$ \\
3,6,8TMI, pH 5 & $40.32 \pm 0.53$ & $5.64 \pm 0.01$ & $7.14 \pm 0.09$ \\
3,6,8TMI, pH 11 & $36.07 \pm 0.18$ & $5.66 \pm 0.01$ & $6.37 \pm 0.03$
\end{tabular}

${ }^{a}$ Values are $\pm 95 \%$ confidence limits.

5 to 11 . The change in $k_{\mathrm{q}}$ for $3,6,8 \mathrm{TMI}$ at these $\mathrm{pH}$ values is insignificant (1.1-fold) and is most likely due to random error. Thus, these data confirm that deprotonation occurs at N3 and that $6,8 \mathrm{DMI}$ acquires a negative charge at high $\mathrm{pH}$. Furthermore, the observation of single exponential decays for both the neutral ( $\mathrm{pH} 5$ ) and anionic ( $\mathrm{pH}$ 11) forms of 6,8DMI, with no evidence of any other kinetic trends (i.e., negative preexponentials or additional exponentials ${ }^{13}$ ), supports the conclusion from the spectral results that an excited-state reaction model is not required.

\section{Computational Results}

Absorption Properties. The ground-state geometry of neutral 6,8DMI, ionized 6,8DMI deprotonated at N3, and 3,6,8TMI were optimized at the MP2 level assuming $C_{s}$ symmetry (see Supporting Information for the optimized geometries). The bond lengths and bond angles of the ring atoms are very similar for $6,8 \mathrm{DMI}$ and $3,6,8 \mathrm{TMI}$. The geometry of the pyrazine ring is essentially unchanged in both the neutral and anionic forms of 6,8DMI. The pyrimidine ring is significantly more affected by the deprotonation of $\mathrm{N} 3$, particularly the atoms connected to $\mathrm{N} 3$. The bond lengths N3-C2 and N3-C4 decreased by 0.057 and $0.052 \AA$, respectively, due to the conjugation of the negative charge to $\mathrm{C} 4-\mathrm{O} 4$ and $\mathrm{C} 2-\mathrm{NH}_{2}$. A change in bond angle $\mathrm{O} 4-$ $\mathrm{C} 4-\mathrm{C} 4 \mathrm{a}$ from $123.0^{\circ}$ in the neutral $6,8 \mathrm{DMI}$ to $130.1^{\circ}$ in the deprotonated 6,8DMI resulted probably from the repulsion between $\mathrm{O} 4$ and the negative charge on N3.

In our previous quantum chemical study we computed the spectroscopic transitions of 6,8DMI in vacuum using TD-DFT. ${ }^{19}$ The present calculations were performed on the absorbing geometries of the neutral and anionic forms 6,8DMI, and also on 3,6,8TMI, in both the absence and presence of an aqueous environment represented by a PCM model. The PCM calculations provide the total solvation energy for each molecule, as well as the electrostatic and nonelectrostatic components of 
TABLE 2: Computed Solvation Energy for the Planar Geometry of Each Molecule

\begin{tabular}{lccc}
\hline \multicolumn{1}{c}{ molecule } & $\begin{array}{c}\text { electrostatic energy } \\
(\mathrm{kcal} / \mathrm{mol})\end{array}$ & $\begin{array}{c}\text { nonelectrostatic } \\
\text { energy }(\mathrm{kcal} / \mathrm{mol})\end{array}$ & $\begin{array}{c}\Delta G_{\text {solv }} \\
(\mathrm{kcal} / \mathrm{mol})\end{array}$ \\
\hline 3,6,8TMI & -25.05 & 7.97 & -17.08 \\
6,8DMI (neutral) & -28.55 & 6.84 & -21.71 \\
6,8DMI (negative) & -69.82 & 6.08 & -63.74
\end{tabular}

this energy (Table 2). The free energy of solvation is largest for the 6,8DMI anion, and smallest for 3,6,8TMI. As expected, the difference in free energy of solvation arises mainly from the electrostatic contribution, which is substantially larger for the anionic form of 6,8DMI. The nonelectrostatic energy is largest for 3,6,8TMI, because the energy required to form an aqueous cavity around this molecule is larger due to the bulky methyl substituent at N3.

The absorption transition energies for each of the three molecules in vacuum are presented in Table 3 . The lowest energy transition for 3,6,8TMI and the neutral form of 6,8DMI occurs at $3.75 \mathrm{eV}(331 \mathrm{~nm})$ and has $n \pi^{*}$ symmetry. 3,6,8TMI and the neutral form of $6,8 \mathrm{DMI}$ undergo a $\pi \pi^{*}$ transition at $3.79 \mathrm{eV}(327 \mathrm{~nm})$ and $3.81 \mathrm{eV}(326 \mathrm{~nm})$, respectively. A higher energy $\pi \pi^{*}$ transition is observed at $4.57 \mathrm{eV}(271 \mathrm{~nm})$ for $3,6,8 \mathrm{TMI}$ and at $4.42 \mathrm{eV}(281 \mathrm{~nm})$ for the neutral 6,8DMI. In the case of the anionic $6,8 \mathrm{DMI}$, the lowest energy transition is of $\pi \pi^{*}$ character, occurring at $3.49 \mathrm{eV}$ (356 nm). However, there is a close-lying $n \pi^{*}$ transition at $3.53 \mathrm{eV}(351 \mathrm{~nm})$. A second $n \pi *$ transition occurs at $3.87 \mathrm{eV}(320 \mathrm{~nm})$, whereas the second $\pi \pi^{*}$ transition is at $4.18 \mathrm{eV}(297 \mathrm{~nm})$.

For comparison with the experimentally determined absorbance spectra, TD-DFT was performed on each molecule using the PCM representation of aqueous solution. Transition energies in good agreement with those measured in buffer were obtained by this approach (Table 4). In each of the three molecules, the lowest energy transition exhibits $\pi \pi^{*}$ symmetry. For $3,6,8 \mathrm{TMI}$ and 6,8DMI this transition occurs at $3.68 \mathrm{eV}(337 \mathrm{~nm})$ and 3.74 $\mathrm{eV}(332 \mathrm{~nm})$, respectively. However, the lowest energy transition of the anionic form of 6,8DMI is red-shifted by $0.11 \mathrm{eV}(10$ $\mathrm{nm})$ to $3.63 \mathrm{eV}(350 \mathrm{~nm})$. The computed shift in wavelength due to the deprotonation of $\mathrm{N} 3$ is consistent with the measured absorbance red shift of $0.13 \mathrm{eV}(12 \mathrm{~nm})$. The computed lowest energy $n \pi *$ transition is higher in energy than the lowest energy $\pi \pi^{*}$ transition in each molecule. Furthermore, the separation between the $n \pi^{*}$ and $\pi \pi^{*}$ states is significantly larger for each molecule when the solvent is taken into account, as compared to the vacuum calculations where the gaps are close to isoenergetic (see Table 3). A second $\pi \pi^{*}$ transition was computed at $4.43 \mathrm{eV}(280 \mathrm{~nm})$ for 3,6,8TMI, $4.45 \mathrm{eV}(279 \mathrm{~nm})$ for 6,8DMI in the neutral form, and $4.35 \mathrm{eV}(285 \mathrm{eV})$ for the anionic $6,8 \mathrm{DMI}$. This transition corresponds to the second peak in the respective absorbance spectra. The anionic form of 6,8DMI has two transitions of nearly degenerate energy at $4.35 \mathrm{eV}(285$ $\mathrm{nm})$, but one has predominantly $n \pi^{*}$ character whereas the other

TABLE 3: TD-DFT Transition Energies Computed from the Ground-State Geometries in Vacuum

\begin{tabular}{lccc}
\hline \multirow{2}{*}{ molecule } & orbitals $^{a}($ symmetry $)$ & $\begin{array}{c}\text { fractional contribution } \\
\text { to transition }\end{array}$ & $E_{\text {calc }}, \mathrm{eV}[\mathrm{nm}]$ \\
\hline \multirow{3}{*}{$3,6,8 \mathrm{TMI}$} & $\mathrm{H} 1(\sigma) \rightarrow \mathrm{L}\left(\pi^{*}\right)$ & 0.919 & $3.75[331]$ \\
& $\mathrm{H}(\pi) \rightarrow \mathrm{L}\left(\pi^{*}\right)$ & 0.787 & $3.79[327]$ \\
6.8DMI (neutral) & $\mathrm{H}(\pi) \rightarrow \mathrm{L} 1\left(\pi^{*}\right)$ & 0.770 & $4.57[271]$ \\
& $\mathrm{H} 1(\sigma) \rightarrow \mathrm{L}\left(\pi^{*}\right)$ & 0.913 & $3.75[331]$ \\
& $\mathrm{H}(\pi) \rightarrow \mathrm{L}\left(\pi^{*}\right)$ & 0.788 & $3.81[326]$ \\
6,8DMI (negative) & $\mathrm{H}(\pi) \rightarrow \mathrm{L} 1\left(\pi^{*}\right)$ & 0.778 & $4.42[281]$ \\
& $\mathrm{H}(\pi) \rightarrow \mathrm{L}\left(\pi^{*}\right)$ & 0.683 & $3.49[356]$ \\
& $\mathrm{H} 1(\sigma) \rightarrow \mathrm{L}\left(\pi^{*}\right)$ & 0.954 & $3.53[351]$ \\
$\mathrm{H} 3(\sigma) \rightarrow \mathrm{L}\left(\pi^{*}\right)$ & 0.106 & $3.87[320]$ \\
& $\mathrm{H} 4(\sigma) \rightarrow \mathrm{L}\left(\pi^{*}\right)$ & 0.982 & $4.18[297]$
\end{tabular}

${ }^{a} \mathrm{H}$ represents HOMO, L represents LUMO, $\mathrm{H} n$ represents $\mathrm{HOMO}-n, \mathrm{~L} n$ represents LUMO $+n .{ }^{b}$ Computed as twice the squared coefficient of the transition in the CI vector; only those transitions with a $5 \%$ or greater contribution are shown.

TABLE 4: TD-DFT Transition Energies Computed from the Ground-State Geometries Using PCM Representation of Water as a Solvent

\begin{tabular}{|c|c|c|c|c|}
\hline molecule & orbitals $^{a}$ (symmetry) & $\begin{array}{l}\text { fractional contribution } \\
\text { to transition }{ }^{b}\end{array}$ & $E_{\text {calc }}, \mathrm{eV}[\mathrm{nm}]$ & $E_{\text {expt }}, \mathrm{eV}[\mathrm{nm}]$ \\
\hline \multirow{5}{*}{$3,6,8 \mathrm{TMI}$} & $\mathrm{H}(\pi) \rightarrow \mathrm{L}\left(\pi^{*}\right)$ & 0.799 & $3.68[337]$ & $3.66[339]$ \\
\hline & $\mathrm{H} 1(\sigma) \rightarrow \mathrm{L}\left(\pi^{*}\right)$ & 0.934 & $4.00[310]$ & $\mathrm{ND}^{c}$ \\
\hline & $\mathrm{H}(\pi) \rightarrow \mathrm{L} 1\left(\pi^{*}\right)$ & 0.671 & \multirow{3}{*}{$4.43[280]$} & \multirow{3}{*}{$4.23[293]$} \\
\hline & $\mathrm{H} 3(\pi) \rightarrow \mathrm{L}\left(\pi^{*}\right)$ & 0.087 & & \\
\hline & $\mathrm{H} 2(\pi) \rightarrow \mathrm{L}\left(\pi^{*}\right)$ & 0.085 & & \\
\hline \multirow{3}{*}{ 6,8DMI (neutral) } & $\mathrm{H}(\pi) \rightarrow \mathrm{L}\left(\pi^{*}\right)$ & 0.796 & $3.74[332]$ & $3.67[338]^{d}$ \\
\hline & $\mathrm{H} 1(\sigma) \rightarrow \mathrm{L}\left(\pi^{*}\right)$ & 0.936 & $3.99[310]$ & ND \\
\hline & $\mathrm{H}(\pi) \rightarrow \operatorname{L} 1\left(\pi^{*}\right)$ & 0.794 & $4.45[279]$ & $4.22[294]^{d}$ \\
\hline \multirow{9}{*}{ 6,8DMI (negative) } & $\mathrm{H}(\pi) \rightarrow \mathrm{L}\left(\pi^{*}\right)$ & 0.791 & $3.63[342]$ & $3.54[350]^{e}$ \\
\hline & $\mathrm{H} 2(\sigma) \rightarrow \mathrm{L}\left(\pi^{*}\right)$ & 0.761 & \multirow{3}{*}{$4.04[307]$} & \multirow{3}{*}{ ND } \\
\hline & $\mathrm{H} 3(\sigma) \rightarrow \mathrm{L}\left(\pi^{*}\right)$ & 0.154 & & \\
\hline & $\mathrm{H} 3(\sigma) \rightarrow \mathrm{L}\left(\pi^{*}\right)$ & 0.640 & & \\
\hline & $\mathrm{H} 2(\sigma) \rightarrow \mathrm{L}\left(\pi^{*}\right)$ & 0.149 & \multirow[t]{3}{*}{$4.35[285]$} & \multirow[t]{3}{*}{ ND } \\
\hline & $\mathrm{H} 1(\pi) \rightarrow \mathrm{L}\left(\pi^{*}\right)$ & 0.136 & & \\
\hline & $\mathrm{H} 1(\pi) \rightarrow \mathrm{L}\left(\pi^{*}\right)$ & 0.681 & & \\
\hline & $\mathrm{H} 3(\sigma) \rightarrow \mathrm{L}\left(\pi^{*}\right)$ & 0.117 & \multirow[t]{2}{*}{$4.35[285]$} & \multirow[t]{2}{*}{$4.40[282]^{e}$} \\
\hline & $\mathrm{H}(\pi) \rightarrow \mathrm{L} 1\left(\pi^{*}\right)$ & 0.111 & & \\
\hline
\end{tabular}

${ }^{a} \mathrm{H}$ represents HOMO, L represents LUMO, $\mathrm{H} n$ represents $\mathrm{HOMO}-n, \mathrm{~L} n$ represents LUMO $+n .{ }^{b}$ Computed as twice the squared coefficient of the transition in the CI vector; only those transitions with a $5 \%$ or greater contribution are shown. ${ }^{c} \mathrm{ND}$ : $n \pi *$ transitions were not determined experimentally. ${ }^{d}$ Absorbance data obtained at $\mathrm{pH}$ 5.0. ${ }^{e}$ Absorbance data obtained at $\mathrm{pH}$ 11.0. 


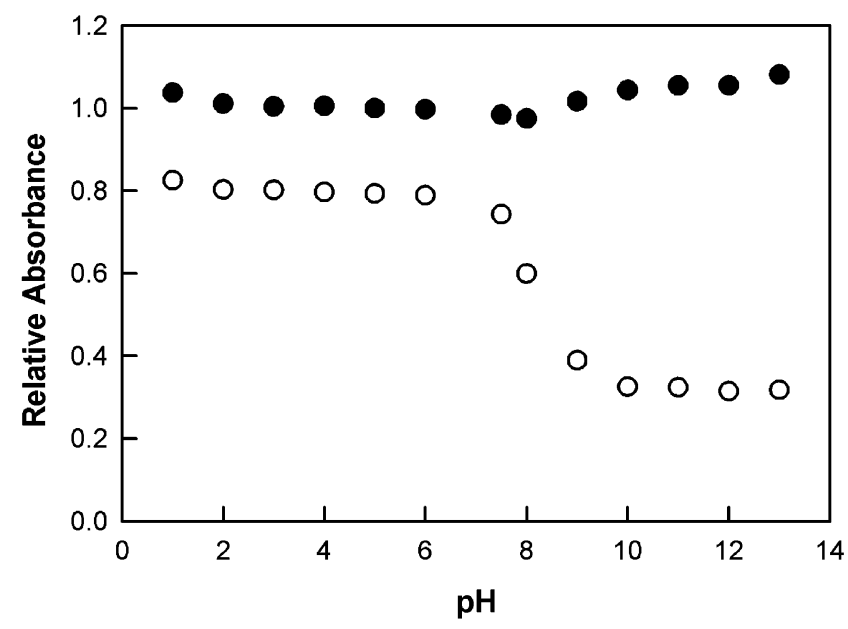

Figure 5. Relative absorption determined at the peak of the first (-) and second $(O)$ lowest energy transitions. Values are relative to the lowest energy peak of 6,8DMI measured at $\mathrm{pH} 5$.

has mainly $\pi \pi^{*}$ character. Thus, the computed absorbance transitions agree energetically with the measured absorbance spectra.

The changes in the absorbance spectra due to the deprotonation at $\mathrm{N} 3$ are now analyzed utilizing the properties of the orbitals involved in the transitions. The relative absorption of the two low-energy transitions of 6,8DMI as a function of $\mathrm{pH}$, determined experimentally by absorption spectroscopy, are shown in Figure 5. Although a small increase in absorption is observed for the lowest energy transition near the $\mathrm{p} K_{\mathrm{a}}$ of 6,8DMI, a dramatic decrease is observed for the higher energy transition. This result suggests that the extinction of the lower energy absorbance transition is not dependent on the protonation state of $6,8 \mathrm{DMI}$ and that the extinction of the higher energy absorbance transition is different for the neutral and anionic forms of 6,8DMI.

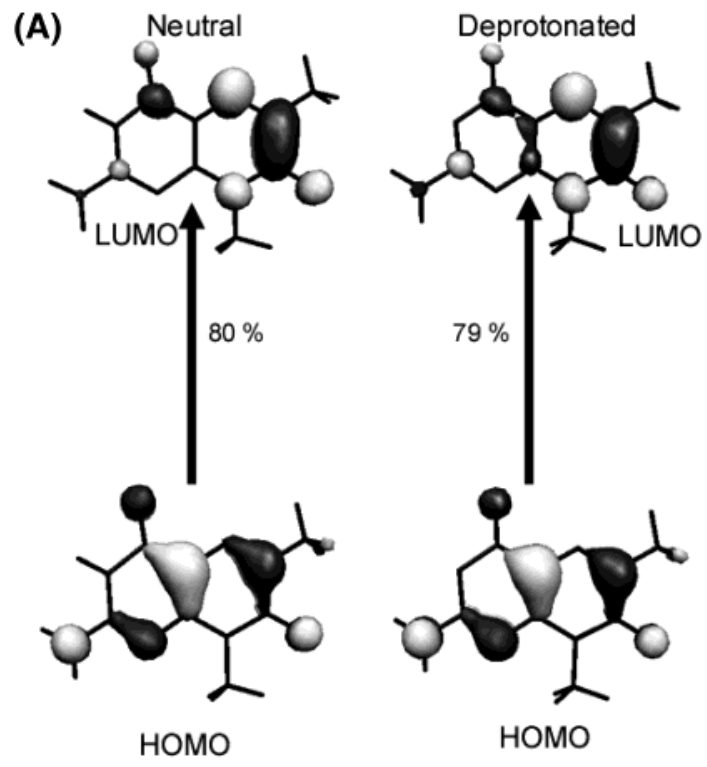

We investigated the orbitals involved in these transitions of the neutral and anionic of 6,8DMI to assess the nature of the observed $\mathrm{pH}$-dependent differences in extinction. In each of the three molecules studied, the promotion of an electron from the ground state to the lowest energy $\pi \pi^{*}$ state mainly involves the highest occupied molecular orbital (HOMO) and the lowest unoccupied molecular orbital (LUMO) (see Table 4 and Figure 6A). The localization of the orbitals is similar in each of the three molecules. The HOMO is predominantly localized on the $\mathrm{C} 8 \mathrm{a}-\mathrm{C} 4 \mathrm{a}$ and $\mathrm{N} 1-\mathrm{C} 2$ bonds. A subtle difference is observed between $3,6,8 \mathrm{TMI}$ and the negative form of $6,8 \mathrm{DMI}$ in that $3,6,8 \mathrm{TMI}$ exhibits greater localization of the HOMO at the N5C6 bond, whereas the HOMO of the negative 6,8DMI is localized at the $\mathrm{C} 6-\mathrm{C} 7$ bond. The HOMO of the neutral form of $6,8 \mathrm{DMI}$ is intermediate between these two cases. The differences in orbital localization are most likely due to an electrostatic effect of the deprotonation of N3. As a result, a red shift in absorbance of the lowest energy band is observed, without significant changes in extinction. Thus, the extinction coefficient for the lowest energy $\pi \pi^{*}$ transition remains constant because the electronic structure of the orbitals that participate in this transition are nearly identical for the neutral and negative forms of 6,8DMI. Significant differences are observed, however, for the transition to the second $\pi \pi^{*}$ state (Figure $6 \mathrm{~B}$ ). In the neutral molecule, $79 \%$ of this transition is accounted for by the transition from the HOMO to the LUMO+1. The LUMO+1 is localized similarly in both the neutral and the anionic forms of 6,8DMI, with bonding character on the $\mathrm{C} 4-\mathrm{C} 4 \mathrm{a}, \mathrm{N} 1-\mathrm{C} 2$, and C7-N8 bonds, and antibonding character on N3, O4, C6, O7, $\mathrm{C} 8 \mathrm{a}$, and the amino nitrogen. However, in the anionic form of $6,8 \mathrm{DMI}$, the transition from HOMO to LUMO +1 accounts for only $11 \%$ of this transition. The transition predominantly $(68 \%)$ involves movement of an electron from HOMO-1 to LUMO. In this case, HOMO- 1 is an antibonding orbital with localization mostly on the pyrimidine ring atoms, particularly N1, N3,

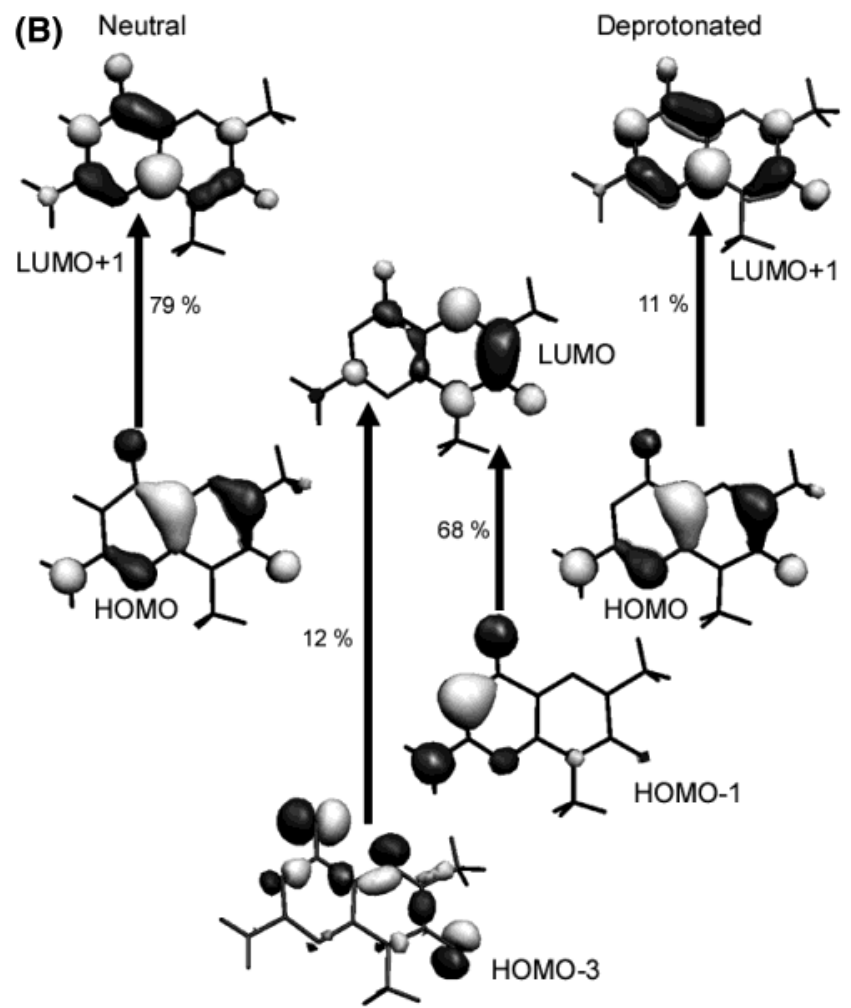

Figure 6. Wave function representation of molecular orbitals involved in the first (A) and second (B) lowest energy absorbance transitions of neutral and deprotonated 6,8DMI computed with TD-DFT. Wave functions were calculated using a PCM representation of water as the solvent. Figures were generated with MOLEKEL 4.1, ${ }^{22,23}$ using a surface cutoff of $0.05\left(\mathrm{e} / \AA^{3}\right)^{1 / 2}$. Light and dark shading represent lobes of opposite sign. 
TABLE 5: Calculated Transition Energies and Oscillator Strengths for the Emitting Geometries in Vacuum and Experimentally Determined Energies of Emission

\begin{tabular}{lcccc}
\hline molecule & orbitals $^{a}($ symmetry $)$ & $\begin{array}{c}\text { fractional contribution } \\
\text { to excited state }\end{array}$ & $E_{\text {calc }}, \mathrm{eV}[\mathrm{nm}]$ & $E_{\text {expt }}, \mathrm{eV}[\mathrm{nm}]$ \\
\hline \multirow{3}{*}{ 3,6,8TMI } & $\mathrm{L}\left(\pi^{*}\right) \rightarrow \mathrm{H}(\pi)$ & 0.757 & $3.25[381]$ & $3.00[413]$ \\
6,8DMI (neutral) & $\mathrm{L}\left(\pi^{*}\right) \rightarrow \mathrm{H} 1(\sigma)$ & 0.921 & $3.61[344]$ & $\mathrm{ND}^{c}$ \\
& $\mathrm{~L}\left(\pi^{*}\right) \rightarrow \mathrm{H}(\pi)$ & 0.618 & $3.24[383]$ & $3.02[410]^{d}$ \\
6,8DMI (negative) & $\mathrm{L}\left(\pi^{*}\right) \rightarrow \mathrm{H} 1(\sigma)$ & 0.879 & $3.59[345]$ & $\mathrm{ND}$ \\
& $\mathrm{L}\left(\pi^{*}\right) \rightarrow \mathrm{H}(\pi)$ & 0.729 & $3.07[404]$ & $2.90[427]^{e}$ \\
& $\mathrm{~L}\left(\pi^{*}\right) \rightarrow \mathrm{H} 1(\sigma)$ & 0.056 & $3.33[372]$ & $\mathrm{ND}$
\end{tabular}

${ }^{a} \mathrm{H}$ represents HOMO, L represents LUMO, $\mathrm{H} n$ represents $\mathrm{HOMO}-n, \mathrm{~L} n$ represents LUMO $+n .{ }^{b}$ Computed as twice the squared coefficient of the transition in the CI vector; only those transitions with a $5 \%$ or greater contribution are shown. ${ }^{c} \mathrm{ND}$ : not determined. ${ }^{d} \mathrm{pH} 5.0 .{ }^{e} \mathrm{pH} 11.0$.

O4, and the amino nitrogen. Because PCM breaks the symmetry of the wave function, ${ }^{26}$ a small contribution $(12 \%)$ of an $n \pi^{*}$ transition, from HOMO-3 to LUMO, is present. Thus we conclude that the large observed change in the extinction coefficient of the second absorbance band is due to differences in the composition of the configuration interaction $(\mathrm{CI})$ vector for this state in the neutral and anionic 6,8DMI. This is evident from the large decrease in oscillator strength for the second $\pi \pi^{*}$ transition of deprotonated $6,8 \mathrm{DMI}(0.0212)$ as compared to neutral 6,8DMI (0.1116).

Emission Properties. To investigate the emission properties, the geometry of the lowest energy $\pi \pi^{*}$ state was optimized using CI singles for each of the molecules studied (see Supporting Information). The emitting states were allowed to assume nonplanar geometry. Several changes are observed in the emitting geometries with respect to the ground-state geometries. In the neutral molecule, several bond lengths were shortened in the transition from the ground- to excited-state geometry. The most significant changes in bond length for the neutral 6,8DMI were found in the $\mathrm{C} 4 \mathrm{a}-\mathrm{N} 5, \mathrm{C} 7-\mathrm{O} 7, \mathrm{C} 4-\mathrm{O} 4$, and $\mathrm{N} 1-\mathrm{C} 8 \mathrm{a}$ bonds. These bonds were also shortened in the anionic form of 6,8DMI, but the magnitude of the decrease was smaller, suggesting less electronic redistribution in this molecule as compared to the neutral $6,8 \mathrm{DMI}$. In each molecule, the pyrimidine ring remained essentially planar, and the pyrazine ring became puckered. Specifically, C6 moved below the plane of the pyrimidine ring by $0.37 \AA$, and N8 moved above this plane by $0.33 \AA$. The bond lengths and angles within the rings of the neutral 6,8DMI and 3,6,8TMI are virtually identical, consistent with the similarities of the emission spectra.

Due to limitations in the current versions of the commercially available quantum chemistry software packages, geometry optimization of solutes using PCM is not feasible. As a result, changes in the wave function due to the reorganization of solvent upon solute electronic excitation are neglected. Therefore, it is not realistic to compute solvated emission energies at the present time, and so all emission energies were computed using TDDFT in vacuum (Table 5). Nevertheless, the transition energy for the $\pi \pi^{*}$ emission of the negative form of $6,8 \mathrm{DMI}$ was found to be lower than that of the neutral form of $6,8 \mathrm{DMI}$. This result is consistent with the experimental observation that the fluorescence emission of $6,8 \mathrm{DMI}$ is red-shifted at higher $\mathrm{pH}$. Furthermore, the calculated shift in emission wavelength, 15 $\mathrm{nm}$, is in very close agreement with the experimentally observed shift of $17 \mathrm{~nm}$.

In all cases, the lowest lying transition has $\pi \pi^{*}$ symmetry, and emission from this state to the ground state predominantly involves a transition from the LUMO to the HOMO. Localizations of these orbitals are similar for all three molecules studied (data not shown).

\section{Summary}

Pseudo intrinsic base analogues with high fluorescence quantum yields are important for the study of local DNA structure and dynamics. The base analogue $3 \mathrm{MI}$ has been successfully applied to the study of important biological problems, including DNA repair, ${ }^{27}$ binding of histones to DNA, ${ }^{28}$ and binding of HIV-1 integrase to DNA. ${ }^{29}$ DNA base flipping, however, is strongly dependent on hydrogen bonding, and therefore, 6MI would be better suited to the study of such processes. Thus we have performed a detailed characterization of the chemical and photophysical properties of $6,8 \mathrm{DMI}$ as a model for 6MI. The combination of spectroscopy experiments and quantum chemical calculations has provided the $\mathrm{p} K_{\mathrm{a}}$ of $6,8 \mathrm{DMI}$, and a detailed understanding of the dependence of the extinction coefficient of the higher energy $\pi \pi^{*}$ transition on the protonation state. The $\mathrm{p} K_{\mathrm{a}}$ 's for the deprotonation of 6,8DMI at $\mathrm{N} 3$ in the ground state (8.3) and lowest energy $\pi \pi^{*}$ excited state (8.5) are similar. Because the $\mathrm{p} K_{\mathrm{a}}$ is in the physiological range, the change in absorbance and emission spectra due to deprotonation of $\mathrm{N} 3$ must be accounted for when interpreting absorbance and emission data in this $\mathrm{pH}$ range. The absorbance transitions computed in the presence of a PCM representation of water are in agreement with the experimental values. Investigation of ground- and excited-state molecular orbitals provided an explanation of the observed changes in the extinction coefficients of the protonation states of $6,8 \mathrm{DMI}$. Inclusion of PCM in the geometry optimization of the excited state is important to accurately reproduce the experimental emission properties. Implementation of the adapted PCM methods ${ }^{30}$ into the commercially available quantum chemistry packages will allow such calculations to be performed. Whereas this study focused on the base analogue in solution, future experiments with the probe incorporated in DNA are necessary to determine the effect of hydrogen bonding on the $\mathrm{p} K_{\mathrm{a}}$ of $\mathrm{N} 3$. Furthermore, the characterization of local DNA structure and dynamics using 6MI will rely on the understanding of its properties presented here.

Acknowledgment. This work was supported by PHS Grant CA 63317. E.S. was supported by training grants GM08553 and CA78207. Fluorescence lifetime studies were performed on an instrument developed under NSF grant DBI-9724330. Preliminary results of this work were presented at the 46th Annual Meeting of the Biophysical Society (San Francisco, CA, 2002). A.S.C. was a Summer Undergraduate Research Fellow at Mount Sinai School of Medicine.

Supporting Information Available: Tables of bond lengths and angles at the MP2 level and with CI singles. This material is available free of charge via the Internet at http://pubs.acs.org. 


\section{References and Notes}

(1) Nir, E.; Kleinermanns, K.; Grace, L.; de Vries, M. S. J. Phys. Chem. A 2001, 105, 5106-5110.

(2) Jiao, Y.; Stringfellow, S.; Yu, H. J. Biomol. Struct. Dyn. 2002, 19, 929-34

(3) Walter, N. G.; Harris, D. A.; Pereira, M. J.; Rueda, D. Biopolymers 2001, 61, 224-42.

(4) Rachofsky, E. L.; Ross, J. B.; Osman, R. Comb. Chem. High. Throughput Screen. 2001, 4, 675-706.

(5) Stivers, J. T. Nucl. Acids Res. 1998, 26, 3837-44.

(6) Stivers, J. T.; Pankiewicz, K. W.; Watanabe, K. A. Biochemistry 1999, 38, 952-63.

(7) Seibert, E.; Ross, J. B. A.; Osman, R. Biochemistry 2002, 41, 10976-10984.

(8) Hawkins, M. E. Cell Biochem. Biophys. 2001, 34, 257-81.

(9) Hawkins, M. E.; Pfleiderer, W.; Balis, F. M.; Porter, D.; Knutson, J. R. Anal. Biochem. 1997, 244, 86-95.

(10) Driscoll, S. L.; Hawkins, M. E.; Balis, F. M.; Pfleiderer, W.; Laws, W. R. Biophys. J. 1997, 73, 3277-86.

(11) Pfleiderer, W.; Rukwied, M. Chem. Ber. 1961, 94, 1-12.

(12) Rachofsky, E. L.; Osman, R.; Ross, J. B. A. Biochemistry 2001, 40, 946-956.

(13) Lakowicz, J. R. Principles of fluorescence spectroscopy, 2nd ed.; Kluwer Academic/Plenum Publishers: New York, 1999.

(14) Grinvald, A.; Steinberg, I. Z. Anal. Biochem. 1974, 59, 583-98.

(15) Bevington, P. R. Data reduction for the physical sciences; McGrawHill: New York, 1969

(16) Straume, M.; Frasier-Cadoret, S. G.; Johnson, M. L. Least-squares analysis of fluorescence data. In Topics in Fluorescence Spectroscopy; Lakowicz, J. R., Ed., 1991; Vol. 2, pp 177-240.

(17) SPSS. SPSS for Windows, Release 10.0.5 ed.; SPSS Inc.: Chicago, IL, 1999.

(18) Frisch, M. J.; Trucks, G. W.; Schlegel, H. B.; Scuseria, G. E.; Robb, M. A.; Cheeseman, J. R.; Zakrzewski, V. G.; Montgomery, J. A.; Stratmann,
R. E.; Burant, J. C.; Dapprich, S.; Millam, J. M.; Daniels, A. D.; Kudin, K. N.; Strain, M. C.; Farkas, O.; Tomasi, J.; Barone, V.; Cossi, M.; Cammi, R.; Mennucci, B.; Pomelli, C.; Adamo, C.; Clifford, S.; Ochterski, J.; Petersson, G. A.; Ayala, P. Y.; Cui, Q.; Morokuma, K.; Malick, D. K.; Rabuck, A. D.; Raghavachari, K.; Foresman, J. B.; Cioslowski, J.; Ortiz, J. V.; Stefanov, B. B.; Liu, G.; Liashenko, A.; Piskorz, P.; Komaromi, I.; Gomperts, R.; Martin, R. L.; Fox, D. J.; Keith, T.; Al-Laham, M. A.; Peng, C. Y.; Nanayakkara, A.; Gonzalez, C.; Challacombe, M.; Gill, P. M. W.; Johnson, B. G.; Chen, W.; Wong, M. W.; Andres, J. L.; Head-Gordon, M.; Replogle, E. S.; Pople, J. A. Gaussian 98; Gaussian Inc.: Pittsburgh, PA, 1998.

(19) Seibert, E.; Ross, J. B. A.; Osman, R. Int. J. Quantum Chem. 2002, $88,28-33$

(20) Miertus, S.; Tomasi, J. Chem. Phys. 1982, 65, 239-245.

(21) Miertus, S.; Scrocco, E.; Tomasi, J. Chem. Phys. 1981, 55, 117129.

(22) Flükiger, P.; Lüthi, H. P.; Portmann, S.; Weber, J. MOLEKEL, 4.1 ed.; Swiss Center for Scientific Computing: Manno, Switzerland, 20002002.

(23) Portmann, S.; Lüthi, H. P. Chimia 2000, 54, 766-770.

(24) Waxman, E.; Rusinova, E.; Hasselbacher, C. A.; Schwartz, G. P.; Laws, W. R.; Ross, J. B. Anal. Biochem. 1993, 210, 425-8.

(25) Bloomfield, V. A.; Crothers, D. M.; Tinoco, I. Nucleic acids: structures, properties and functions; University Science Books: Sausalito, CA, 2000.

(26) Scalmani, G.; Barone, V. Chem. Phys. Lett. 1999, 301, 263-269.

(27) Moser, A. M.; Patel, M.; Yoo, H.; Balis, F. M.; Hawkins, M. E. Anal. Biochem. 2000, 281, 216-22.

(28) Wojtuszewski, K.; Hawkins, M. E.; Cole, J. L.; Mukerji, I. Biochemistry 2001, 40, 2588-98.

(29) Deprez, E.; Tauc, P.; Leh, H.; Mouscadet, J. F.; Auclair, C.; Hawkins, M. E.; Brochon, J. C. Proc. Natl. Acad. Sci. U.S.A. 2001, 98 10090-5.

(30) Mennucci, B.; Toniolo, A.; Tomasi, J. J. Am. Chem. Soc. 2000, $122,10621-10630$ 